\section{Roberta Schein Bigio'}

Eliseu Verly Junior'

Michelle Alessandra de Castro'

Chester Luiz Galvão César"

Regina Mara Fisberg'II

Dirce Maria Lobo Marchioni"'

Programa de Pós-Graduação em Nutrição em Saúde Pública. Faculdade de Saúde Pública (FSP). Universidade de São Paulo (USP). São Paulo, SP, Brasil

" Departamento de Epidemiologia. FSP-USP. São Paulo, SP, Brasil

III Departamento de Nutrição. FSP-USP. São Paulo, SP, Brasil

\section{Correspondence:}

Dirce Maria Lobo Marchioni

Faculdade de Saúde Pública da USP

Av. Doutor Arnaldo, 715

01246-904 São Paulo, SP, Brasil

E-mail:marchioni@usp.br

\section{Determinants of fruit and vegetable intake in adolescents using quantile regression}

\begin{abstract}
OBJECTIVE: To analyze fruit and vegetable intake in adolescents and to identify associated factors.

METHODS: A population-based cross-sectional study was conducted with a representative sample of 812 adolescents of both sexes in the city of São Paulo, Southeastern Brazil, in 2003. Food consumption was measured with the 24-hour dietary recall. Fruit and vegetable intake was described in percentiles. Quantile regression models were used to investigate the association between this intake and explanatory variables.
\end{abstract}

RESULTS: Of all adolescents interviewed, $6.4 \%$ consumed the minimum recommendation of $400 \mathrm{~g}$ /day of fruits and vegetables and $22 \%$ did not consume any type of fruits and vegetables. According to quantile regression models, adjusted for energy intake, age group and sex, per capita household income and head of household's level of education were positively associated with fruit and vegetable intake, whereas smoking habit showed a negative association. Income was significantly associated with lower intake percentiles (p20 to p55); smoking, with intermediate percentiles (p45 to p75); and head of household's level of education, with higher percentiles (p70 to 95).

CONCLUSIONS: Fruit and vegetable intake among adolescents of São Paulo was below the Ministry of Health's recommendations and it is influenced by per capita household income, head of family's level of education and smoking habit.

DESCRIPTORS: Adolescent. Food Consumption. Fruit. Vegetables. Socioeconomic Factors.

\section{INTRODUCTION}

Fruits and vegetables are widely known because of their relevant role in human health, ${ }^{\mathrm{a}}$ and their intake seems to have a protective effect on the risk of obesity, ${ }^{2}$ diabetes mellitus type $2,{ }^{2}$ cardiovascular diseases ${ }^{12}$ and certain types of cancer. ${ }^{28,29}$ Estimates of the World Health Organization (WHO) points to approximately 2.7 million deaths worldwide in 2000 that could have been prevented with adequate fruit and vegetable intake, which would reduce global burden of disease by $1.8 \% .^{18}$

As a non-communicable chronic disease prevention strategy, the WHO and the Brazilian Ministry of Health recommend a minimum intake of $400 \mathrm{~g}$ per day of fruits and vegetables (equivalent to five portions). ${ }^{29}$

Ministério da Saúde. Secretaria de Atenção à Saúde. Coordenação Geral da Política de Alimentação e Nutrição. Guia alimentar da população brasileira: promovendo a alimentação sudável. Brasília, DF; 2005. (Série A. Normas e Manuais Técnicos). [Cited 2011 Jan 25]. Available from: http://dtr2001.saude.gov.br/editora/produtos/livros/pdf/05_1109_M.pdf 
The 2002-2003 Pesquisa de Orçamentos Familiares (Household Budget Survey) recommends that the caloric contribution of fruits and vegetables in diet be $2.3 \% .^{7}$ In an analysis of food availability trend in Brazilian households, Levy-Costa et al (2005) ${ }^{17}$ observed that this contribution has remained low in the last 30 years.

In Brazil, estimates of fruit and vegetable intake among adolescents are scarce and, in their majority, originate from studies conducted with non-representative samples. In addition, the food frequency questionnaire, the method of investigation generally used, does not provide accurate intake measurements. ${ }^{5,21}$

The present study aimed to analyze fruit and vegetable intake among adolescents and to identify associated factors.

\section{METHODS}

A population-based cross-sectional study was conducted in 2003, resulting from the multicenter research project entitled Inquérito de Saúde de São Paulo (ISA-Capital - City of São Paulo Health Survey). The ISA-Capital was developed to collect data on the health and diet of adolescents, adults and elderly individuals of the city of São Paulo, Souhteastern Brazil. The present study used data on 812 adolescents aged between 12 and 19 years. Sample was stratified into clusters, in two stages: census tract and household. More details on the sampling process can be found in Castro et al. ${ }^{6}$

Qualified interviewers conducted a household survey with a structured questionnaire to investigate demographic, anthropometric, socioeconomic, family and lifestyle characteristics.

Food intake was measured with the 24-hour dietary recall, a method applied according to the multiplepass method, structured in five steps: 1) quick list, where participants list all the foods and beverages consumed uninterruptedly; 2) forgotten list, where participants are asked about commonly forgotten foods consumed, such as candies, coffees and sodas; 3) time and location of food and beverage intake; 4) detailing cycle, where the way of preparation and amounts consumed are described; and 5) final review, which verifies whether a certain food consumed during the day was not previously recorded. ${ }^{20}$ This method helps individuals to recall foods and beverages consumed on the day before the interview and to record them in a detailed way, thus reducing dietary measurement errors. ${ }^{24}$ Adolescents were instructed to record the foods consumed according to household measures and to mention the way of preparation, seasonings and commercial brands.
Information about food intake was reviewed to identify possible errors of completion and to convert household measures of foods and beverages into grams and milliliters, respectively. ${ }^{23}$ The Nutrition Data System for Research (NDS) software was used (2007 version, NCC, University of Minnesota, Minneapolis, USA) to obtain nutritional values.

Daily intake (in grams) of fruits and vegetables was calculated to create the fruit and vegetable variable. This variable was comprised of all types of fruits and vegetables, whether they were consumed raw or cooked, peeled or unpeeled, including those used as ingredients in preparations. Researchers chose to quantify foods of the fruit and vegetable group included in preparations such as soups, side dishes and mixed dishes, aiming to measure all and every type of fruit and vegetable consumed, thus avoiding an underestimated intake of this food group. The preparations recorded in the 24-hour recall were quantified, typed and separated into their respective ingredients. Foods from the group of roots and tubers, such as potato, cassava and yam, were excluded because they do not belong to the fruit and vegetable group, according to the Guia Alimentar da População Brasileira (Brazilian Population Food Guide). ${ }^{\mathrm{a}}$ Fruit and vegetable intake was considered adequate when equal to or higher than $400 \mathrm{~g} / \mathrm{day}$, according to the Ministry of Health recommendations. ${ }^{\text {a }}$

Classification of the nutritional status was based on the cut-off points of Body Mass Index (BMI) according to sex and age proposed by the WHO. ${ }^{22}$ Anthropometric measurements of self-reported weight and height were used to calculate BMI. Overweight or obese adolescents were grouped and classified as weight excess.

Adolescents who reported alcohol consumption, regardless of the type of beverage, frequency and quantity, were categorized as alcohol drinkers. Current or previous smoking habit was considered to define adolescents as smokers.

Per capita household income was estimated by adding the monthly incomes of all individuals of a household, divided by the total number of residents. A total of two categories of per capita household income were defined (up to one minimum wage; more than one minimum wage), according to the value of a minimum wage at the time of this study (R\$ 240.00 or US\$ 75.00).

Head of household's level of education was categorized according to the number of years of school completed (up to eight years; nine years or more).

Fruit and vegetable intake was stratified by sex and described as percentiles. Quantile regression models were constructed to identify the association between 
fruit and vegetable intake and the variables analyzed. These models enable the effect of independent variables on different points of the distribution of the dependent variable to be observed and they are also appropriate when this variable is asymmetric and heteroscedastic, compared to the remaining variables in the model. ${ }^{4}$

Fruit and vegetable intake (grams/day) was the dependent variable. Dichotomous variables (head of household's level of education, per capita household income, smoking habit, drinking and age group) and continuous variables (energy (kcal/day) and BMI-for-age Z-score) were tested as independent variables.

Modeling was performed using the stepwise-forward procedure and the associated variables whose $95 \%$ confidence interval did not include zero remained in the model. Regression coefficients were simultaneously estimated at every five percentiles in the interval between the $20^{\text {th }}$ and $95^{\text {th }}$ percentiles of the same model to analyze the effect of independent variables throughout the entire distribution. This interval characterizes the distribution points in which fruit and vegetable intake is different from zero. Standard error for each of the estimated coefficients was calculated from the 400 replications, using the Bootstrap replication technique. Associations observed in a certain percentile may not be significant in another, because regression coefficients were estimated in several points of distribution. The selection of models that achieved the best adjustments was based on the following two criteria: 1) association of explanatory variables in the highest number of percentiles; and 2) lowest confidence intervals of the coefficients of the main associated variables.

Stata statistical software (Statistics/Data Analysis, version 10.1, Texas, USA) was used in the analysis. The present study was approved by the Research Ethics Committee of the Faculdade de Saúde Pública da Universidade de São Paulo School of Public Health (Process 381, on 2/13/2001).

\section{RESULTS}

The prevalence of overweight was 19\%; smoking habit, $10 \%$; and alcohol drinking, 39\%. Among approximately $57 \%$ of adolescents, heads of households had eight years of education and $52 \%$ belonged to families with incomes equal to or lower than $\mathrm{R} \$ 240.00$ (up to one minimum wage) (Table 1).

About $20 \%$ of adolescents did not consume fruits and vegetables on the day reported and $6.5 \%$ had an adequate intake ( $\geq 400 \mathrm{~g} /$ day). Intake was also adequate between the $90^{\text {th }}$ and $95^{\text {th }}$ percentiles of distribution, in the majority of variables investigated in the analysis stratified by sex (Table 1). The proportion of individuals

Table 1. Percentages of fruit and vegetable intake (in grams) per adolescents, according to sociodemographic characteristics, lifestyle and nutritional status, stratified by sex. Municipality of São Paulo, Southeastern Brazil, 2003.

\begin{tabular}{|c|c|c|c|c|c|c|c|c|c|c|c|c|c|c|c|c|}
\hline \multirow{2}{*}{ Variable } & \multicolumn{8}{|c|}{ Male } & \multicolumn{8}{|c|}{ Female } \\
\hline & $\mathrm{n}$ & $\%$ & P5 & P25 & P50 & P75 & P90 & P95 & $\mathrm{n}$ & $\%$ & P5 & P25 & P50 & P75 & P90 & P95 \\
\hline \multicolumn{17}{|l|}{ Age (years) } \\
\hline 12 to 15 & 196 & 46.5 & 0 & 0 & 66.7 & 172.4 & 307.0 & 460.3 & 183 & 46.8 & 0 & 15.4 & 62.5 & 157.5 & 319.9 & 407.6 \\
\hline 16 to 19 & 225 & 53.5 & 0 & 0.5 & 51.7 & 148.5 & 330.0 & 565.9 & 208 & 53.2 & 0 & 16.3 & 69.6 & 177.7 & 336.2 & 432.0 \\
\hline \multicolumn{17}{|l|}{ Overweight } \\
\hline Yes & 69 & 19.3 & 0 & 5.2 & 80.0 & 170.0 & 360.3 & 461.6 & 63 & 19.3 & 0 & 38.5 & 98.4 & 191.4 & 299.2 & 417.5 \\
\hline No & 289 & 80.7 & 0 & 0 & 51.7 & 162.0 & 330.0 & 534.0 & 264 & 80.7 & 0 & 15.5 & 65.8 & 163.9 & 330.0 & 432.0 \\
\hline \multicolumn{17}{|l|}{ Smoking } \\
\hline Yes & 47 & 11.3 & 0 & 0 & 40.0 & 68.5 & 298.0 & 330.0 & 34 & 8.7 & 0 & 5.7 & 71.3 & 174.0 & 403.5 & 422.4 \\
\hline No & 369 & 88.7 & 0 & 3.2 & 65.1 & 169.8 & 342.6 & 496.0 & 355 & 91.3 & 0 & 15.5 & 65.9 & 171.5 & 324.0 & 437.0 \\
\hline \multicolumn{17}{|c|}{ Alcohol drinking } \\
\hline Yes & 163 & 39.2 & 0 & 0 & 42.3 & 120.0 & 280.0 & 430.0 & 150 & 38.9 & 0 & 15.0 & 76.1 & 175.5 & 295.9 & 362.5 \\
\hline No & 253 & 60.8 & 0 & 12.0 & 70.1 & 180.8 & 348.0 & 493.2 & 236 & 61.1 & 0 & 15.4 & 58.9 & 155.8 & 336.2 & 450.0 \\
\hline \multicolumn{17}{|c|}{ Head of household's level of education (completed years) } \\
\hline 0 to 8 & 242 & 58.2 & 0 & 0 & 40.0 & 118.2 & 223.2 & 398.2 & 215 & 55.7 & 0 & 12.5 & 62.5 & 152.3 & 311.0 & 403.5 \\
\hline 9 or more & 174 & 41.8 & 0 & 20.4 & 90.7 & 232.7 & 378.4 & 545.2 & 171 & 44.3 & 0 & 20.0 & 69.6 & 179.9 & 324.0 & 546.0 \\
\hline \multicolumn{17}{|c|}{ Household income (minimum wages) ${ }^{\mathbf{a}}$} \\
\hline Up to one & 219 & 54.5 & 0 & 0 & 40.0 & 134.5 & 299.6 & 460.3 & 180 & 49.0 & 0 & 1.5 & 51.2 & 163.9 & 348.1 & 415.0 \\
\hline $\begin{array}{l}\text { More than } \\
\text { one }\end{array}$ & 183 & 45.5 & 0 & 26.6 & 81.3 & 198.0 & 370.0 & 496.0 & 187 & 51.0 & 0 & 29.7 & 74.5 & 174.0 & 299.2 & 437.0 \\
\hline
\end{tabular}

a Per capita household income in minimum wages at the time of the study (R\$240.00 or US\$75.00) 


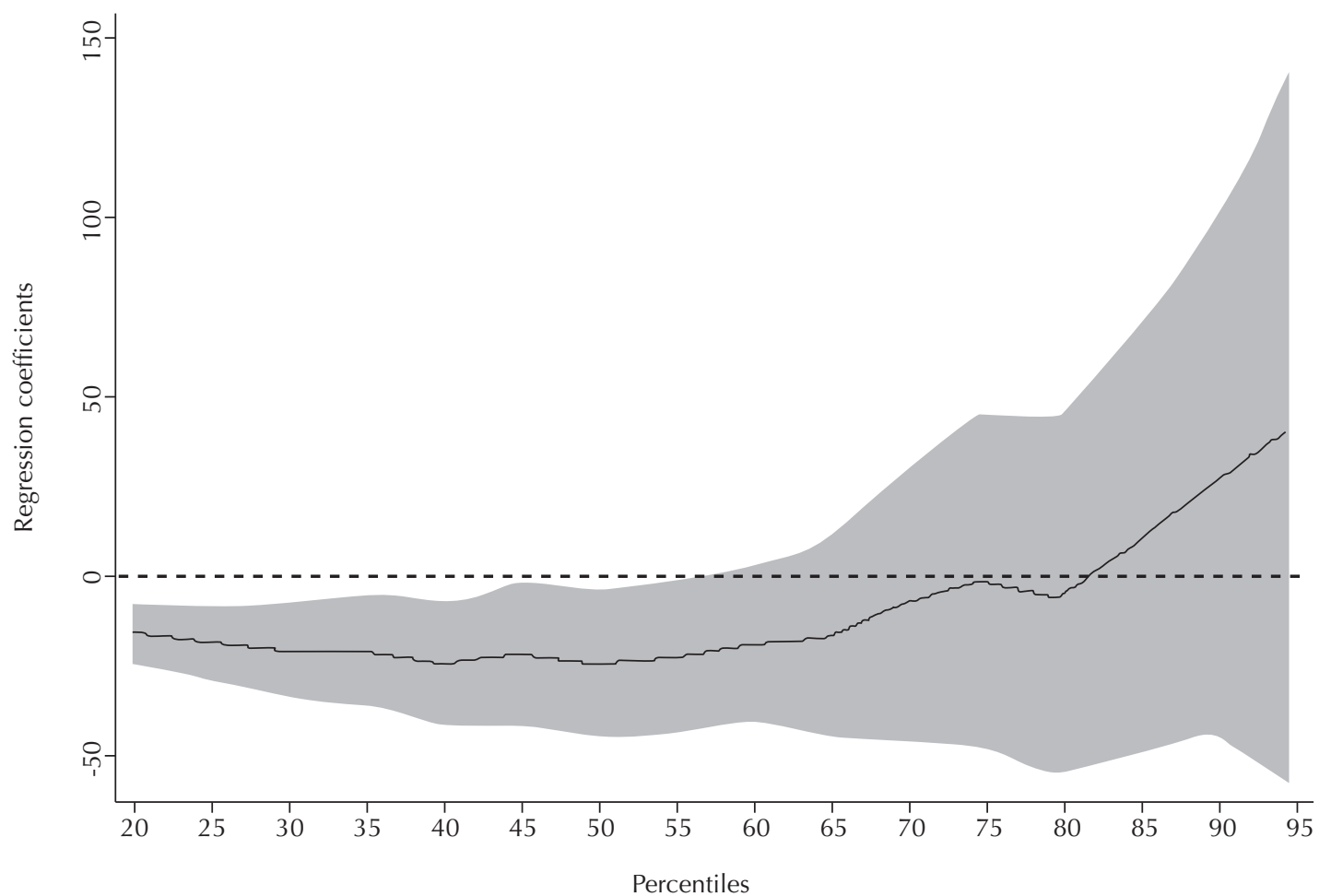

Notes: Coefficients adjusted for smoking habit, head of household's level of education, caloric intake and BMI-per-age Z-score. The gray area corresponds to the 95\% confidence interval. Per capita household income: dichotomous variable, reference category: "more than one minimum wage".

Figure 1. Quantile regression coefficients by per capita household income and fruits and vegetables intake in adolescents. Municipality of São Paulo, Southeastern Brazil, 2003.

with an intake higher than this recommendation was lower than $10 \%$ in all strata analyzed, except for female smokers, whose $90^{\text {th }}$ percentile was $403 \mathrm{~g}$.

The model that best met the criteria had "per capita household income", "head of household's level of education" and "smoking habit" as explanatory variables, adjusted for caloric intake, age group and sex. Figures 1 and 2 show the changes in regression coefficients throughout the distribution, with regards to head of household's level of education and income. These coefficients show the difference of fruit and vegetable intake in grams among the categories of independent variables analyzed. In these graphs, the gray area represents the $95 \%$ confidence interval of coefficients estimated in each percentile. Income was positively associated with fruit and vegetable intake in the $20^{\text {th }}$ to $55^{\text {th }}$ percentiles.

Coefficients remained almost constant between these percentiles, indicating an intake of approximately 20 $\mathrm{g}$ less in the group with the lowest income. Head of household's higher level of education had a significant influence after the $70^{\text {th }}$ percentile and this effect varied with the increase in percentiles. The difference in fruit and vegetable intake between the categories with the highest and lowest level of education was $63 \mathrm{~g}$ in the $70^{\text {th }}$ percentile and $77 \mathrm{~g}$ in the $90^{\text {th }}$ percentile, regardless of the remaining variables.

After the $45^{\text {th }}$ percentile, the effect of smoking habit on fruit and vegetable intake was significant and it gradually increased until the $75^{\text {th }}$ percentile (Figure 3 ). The group of smokers showed an intake of $20 \mathrm{~g}$ and $65 \mathrm{~g}$ less than that of the group of non-smokers in the $45^{\text {th }}$ and $75^{\text {th }}$ percentiles, respectively.

\section{DISCUSSION}

In the present study, $6.5 \%$ of adolescents met the recommended fruit and vegetable intake ( $\geq 400 \mathrm{~g} /$ day). Income, head of household's level of education and smoking habit had an effect on the intake of this food group.

Although there are differences in dietary assessment methods, the results of the present study corroborate those of Brazilian studies on adolescents. Crosssectional studies using food frequency questionnaires found low intake of fruits and vegetables in Brazilian adolescents. ${ }^{1,25}$ In a study conducted by the Instituto Nacional do Câncer (INCA), approximately half (45\%) of adolescents aged between 15 and 24 years, living in 


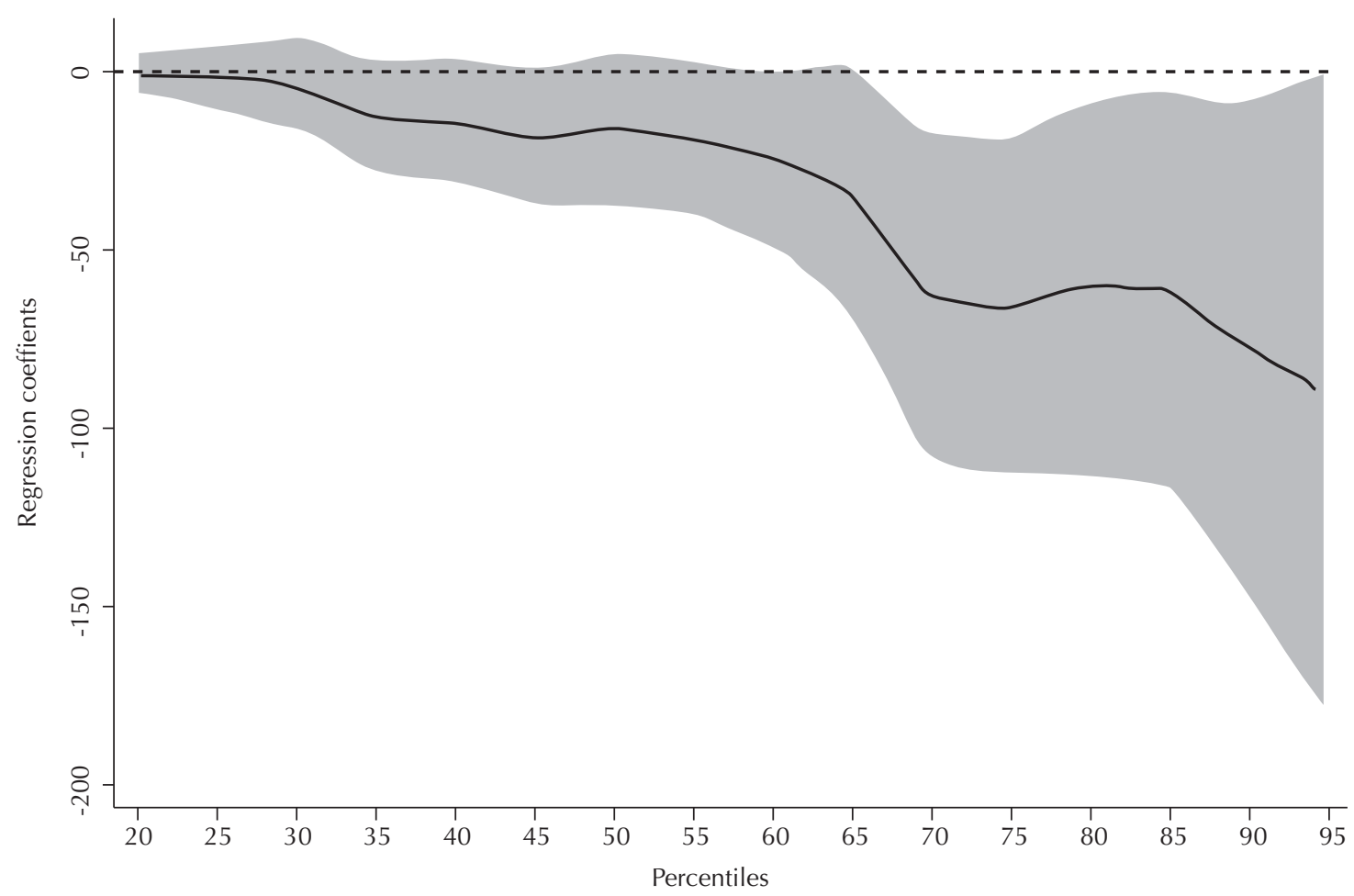

Notes: Coefficients adjusted for smoking habit, caloric intake and BMI-per-age Z-score. The gray area corresponds to the $95 \%$ confidence interval. Head of household's level of education: dichotomous variable, reference category was the group with the highest level of education.

Figure 2. Quantile regression coefficients by head of household's level of education and fruits and vegetables intake in adolescents. Minicipality of São Paulo, Southeastern Brazil, 2003.

the city of São Paulo, SP, consumed fruits or vegetables less than five times per week. ${ }^{\mathrm{b}}$ Among $8^{\text {th }}$ grade students of municipal public schools of the city of Rio de Janeiro, Southeastern, raw and cooked vegetables were consumed at least five times per week by $20 \%$ and $16.5 \%$ of the adolescents studied, respectively. ${ }^{5}$

Recent North American studies have reported a low fruit and vegetable intake among adolescents. ${ }^{11,15,16}$ However, differences in the categorization of food groups, with the inclusion of potatoes and other tubers in the fruit and vegetable group, restricted the comparison of results. Data from the 2003-2004 National Health and Nutrition Examination Survey (NHANES III), for example, showed that potatoes represented approximately $41 \%$ of the total intake of vegetables. ${ }^{15}$

Quantile regression models, used to investigate the association between fruit and vegetable intake and explanatory variables, are extensively applied in econometrics, although being rarely used in health sciences, especially in nutritional epidemiology. The study conducted by Variyam et $\mathrm{al}^{27}$ on factors associated with nutrient intake using such models is one of the exceptions. In the present study, the choice for this particular model is justified by the asymmetry to the right of the curve of fruit and vegetable intake and to the heteroscedasticity of the dependent variable, in relation to the explanatory variables. In these cases, models based on the method of minimum squares create residues that can have a non-uniform variance, resulting in inferences originated from the biased coefficients. When there is no homoscedasticity, certain percentiles may be more influenced by explanatory variables than others. Finally, quantile regression models are additive, i.e. regression coefficients are interpreted as the change in a certain percentile of the dependent variable, caused by the change of an independent variable unit.

Multiple analyses show differences in the influence of income and head of household's level of education on fruit and vegetable intake among adolescents, similarly to what was observed in studies that used linear regression models. ${ }^{26}$ Income was significantly associated in the lower intake percentiles (p20 to p55), whereas level of education was only associated in the highest percentiles of distribution (p70 to p95).

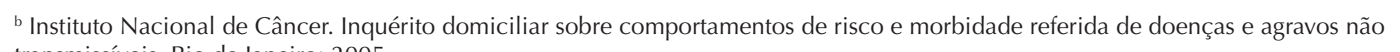
transmissíveis. Rio de Janeiro; 2005. 


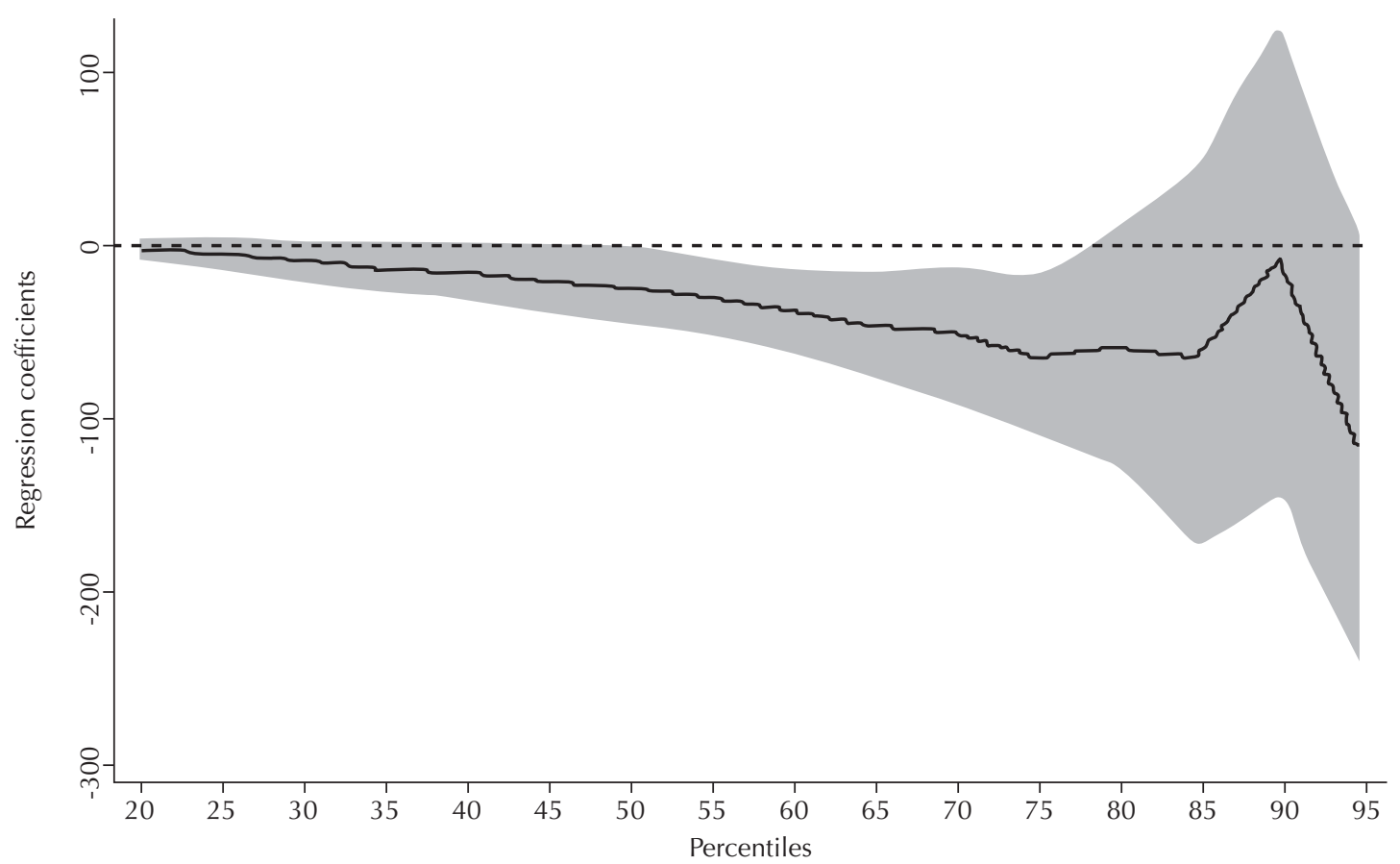

Notes: Coefficients adjusted for head of household's level of education, caloric intake and BMI-per-age Z-score. The gray area corresponds to the $95 \%$ confidence interval. Smoking habit: dichotomous variable, reference category was the group of non-smokers.

Figure 3. Quantile regression coefficients by smoking habit and fruits and vegetables intake in adolescents. Municipality of São Paulo, Southeastern Brazil, 2003.

Income can be a determinant among adolescents who consume low amounts of fruits and vegetables $(75 \mathrm{~g}$ or less, i.e. lower than one daily portion). Among those with a higher intake (between $140 \mathrm{~g}$ and $460 \mathrm{~g}$ ), head of household's level of education became a determinant.

The role of variables in fruit and vegetable intake has been investigated in different studies. ${ }^{7,26}$ Income influences access to and availability of financial resources to purchase more expensive foods, such as fruits and vegetables. ${ }^{25}$ In the present study, where $52 \%$ of adolescents had a per capita household income equal to or lower than R \$240.00 (US\$ 75.00), low intake of fruits and vegetables can be attributed to the lower purchasing power of families, which would restrict the amount of fruits and vegetables available in the household.

Level of education, in its turn, would influence the foods selected, because it provides an individual with the ability to assimilate messages from nutritional education programs and understand the importance of eating as a way to promote health. ${ }^{26}$ In the present study, the higher level of education of a head of household could influence adolescents to consume more fruits and vegetables, as a result of this head of household's choice for healthier foods, once they are main responsible for family decisions.

Smoking habit has an effect on fruit and vegetable intake between the $45^{\text {th }}$ and $75^{\text {th }}$ percentiles of intake, regardless of the influence of income and head of household's level of education. These findings suggest that the effects of smoking habit on fruit and vegetable intake occur on both low (50 g) and moderate levels of intake (165 g). In a population study conducted in Canada, Birkett ${ }^{3}$ observed that smokers consumed a significantly lower amount of fruits and natural fruit juices than non-smokers. In addition, those who consumed a higher number of cigarettes per day were four to six times more likely to eat less fruits than what is recommended. Although less expressive, similar results of fruit and vegetable intake were found. Smokers, however, have increased requirements of antioxidants present in the fruit and vegetable group, because they have lower plasmatic levels of these substances, caused by the excessive amount of free radicals found in cigarette smoke. ${ }^{14}$

Fruit and vegetable intake for each individual was obtained from one single 24-hour recall. This procedure fails to capture daily variations, thus increasing distribution variance. ${ }^{8} \mathrm{An}$ intake lower than the median can be underestimated, whereas that which is higher can be overestimated. Considering the fact that the recommendation of $400 \mathrm{~g} /$ day of fruit and vegetable intake was met in the higher percentiles of distribution, it is possible that the proportion of adolescents with an intake lower than this value is underestimated. Another effect of the increase in variance is the attenuation of measures of 
association between intake and explanatory variables. This implies a possible underestimation of the coefficients found. It is assumed that the associations observed would continue to exist if more than one 24-hour recall was used one per individual, although with coefficients of higher magnitude. Despite the fact that only one dietary measurement reduces the accuracy of percentiles of intake and attenuates regression coefficients, its use does not invalidate the conclusions of this study.

Fruit and vegetable intake is a socially desirable behavior, which can result in over reporting of these foods. ${ }^{13,19}$ However, this type of bias does not seem to be a relevant source of error in the sample studied, once a low percentage of adolescents met the recommendations $(6.5 \%)$ and a higher percentage did not report fruit and vegetable intake (20\%).

Another possible limitation refers to the self-reported

\section{REFERENCES}

1. Andrade RG, Pereira RA, Sichieri R. Consumo alimentar de adolescentes com e sem sobrepeso do Município do Rio de Janeiro. Cad Saude Publica. 2003;19(5):148595. DOI:10.1590/S0102-311X2003000500027

2. Bazzano LA. Dietary Intake of fruit and vegetable and risk of diabetes mellitus and cardiovascular diseases. Geneva: WHO; 2005.

3. Birkett NJ. Intake of fruits and vegetables in smokers. Public Health Nutr. 1999;2(2):217-22. DOI:10.1017/ S1368980099000270

4. Buchinsky M. Recent advancens in quantile regression models: a practical guideline for empirical research. J Hum Resour. 1998;33(1):88-126.

5. Castro IRR, Cardoso LO, Engstrom EM, Levy RB, Monteiro CA. Vigilância de fatores de risco para doenças não transmissíveis entre adolescentes: a experiência da cidade do Rio de Janeiro, Brasil. Cad Saude Publica. 2008;24(10):2279-88. DOI:10.1590/ S0102-311X2008001000009

6. Castro MA, Barros RR, Bueno MB, César CLG, Fisberg RM. Trans fatty acids intake among the population of the city of São Paulo, Brazil. Rev Saude Publica. 2009;43(6):991-7. DOI:10.1590/S003489102009005000084

7. Claro RM, Carmo HCE do, Machado FMS, Monteiro CA. Renda, preço dos alimentos e participação de frutas e hortaliças na dieta. Rev Saude Publica. 2007;41(4):55764. DOI:10.1590/S0034-89102007000400009

8. Dodd KW, Guenther PM, Freedman LS, Subar AF, Kipnis V, Midthune D, et al. Statistical methods for estimating usual intake of nutrients and foods: a review of the theory. J Am Diet Assoc. 2006;106(10):1640-50. DOI:10.1016/j.jada.2006.07.011

9. Farias Júnior JC. Validade das medidas auto-referidas de peso e estatura para o diagnóstico do estado nutricional de adolescentes. Rev. Bras Saude Mater Infant. 2007;7(2):167-74. DOI:10.1590/S151938292007000200007 weight and height, used to calculate the BMI. However, the use of an anthropometric index based on selfreported measurements is described as favorable in a population of adolescents. ${ }^{9 ; 10}$

Fruit and vegetable intake among adolescents of the city of São Paulo is significantly lower than the current recommendations and it is influenced by income, head of household's level of education and smoking habit. Intersectoral actions, aimed to encourage fruit and vegetable intake and the adoption of healthy lifestyles, can improve this situation. The implementation of public policies to reduce the prices of fruits and vegetables, the development of mechanisms that promote an increase in household income and the adoption of multiple nutritional education actions in schools are measures that help to increase fruit and vegetable intake among Brazilian adolescents.

10. Fonseca H, Silva AM, Matos MG, Esteves I, Costa P, Guerra A, et al. Validity of BMI based on selfreported weight and height in adolescents. Acta Paediatr. 2010;99(1):83-8. DOI:10.1111/j.16512227.2009.01518.x

11. Guenther PM, Dodd KW, Reedy J, KrebsSmith SM. Most Americans eat much less than recommended amounts of fruits and vegetables. I Am Diet Assoc. 2006;106(9):1371-9. DOl:10.1016/j. jada.2006.06.002

12. He FJ, Nowson CA, MacGregor GA. Fruit and vegetable consumption and stroke: meta-analysis of cohort studies. Lancet. 2006;367(9507):320-6. DOI:10.1016/S0140-6736(06)68069-0

13. Herbert JR, Hurley TG, Peterson KE, Resnicow K, Thompson FE, Yaroch AL, et al. Social desirability trait influences on self-reported dietary measures among diverse participants in a multicenter multiple risk factor trial. J Nutr. 2008;138(1):226S-34S.

14. Institute of Medicine. Dietary reference intakes for vitamin $\mathrm{C}$, vitamin $\mathrm{E}$, selenium, and carotenoids. Washington, DC: National Academy Press; 2000.

15. Kimmons J, Gillespie C, Seymour J, Serdula M, Blanck HM. Fruit and vegetable intake among adolescents and adults in the United States: percentage meeting individualized recommendations. Medscape J Med. 2009;11(1):26.

16. Larson NI, Neumark-Sztainer DR, Harnack LJ, Wall MM, Story MT, Eisenberg ME. Fruit and vegetable intake correlates during the transition to young adulthood. Am J Prev Med. 2008;35(1):33-7. DOI:10.1016/j.amepre.2008.03.019

17. Levy-Costa RB, Sichieri R, Pontes NS, Monteiro CA. Disponibilidade domiciliar de alimentos no Brasil: distribuição e evolução (1974-2003). Rev Saude Publica. 2005;39(4):530-40. DOI:10.1590/S003489102005000400003 
18. Lock K, Pomerleau J, Altmann DR, McKee M. The global burden of disease attributable to low consumption of fruit and vegetables: implications for the global strategy on diet. Bull World Health Organ. 2005;83(2):100-8. DOI:10.1590/S004296862005000200010

19. Miller TM, Abdel-Msksoud MF, Crane LA, Marcus AC, Byers TE. Effects of social approval bias on self-reported fruit and vegetable consumption: a randomized controlled trial. Nutr J. 2008;7:18. DOI:10.1186/1475-2891-7-18

20. Moshfegh AJ, Rhodes DG, Baer DJ, Murayi T, Clemens JC, Rumpler WV, et al. The US Department of Agriculture automated multiple-pass method reduces bias in the collection of energy intakes. Am J Clin/ Nutr. 2008;88(2):324-32.

21. Nahas MK, Barros MVG, Goldfine BD, Lopes AS, Hallal PC, Farias Júnior JC, et al. Physical activity and eating habits in public high schools from different regions in Brazil: the Saude na Boa Project. Rev Bras Epidemiol. 2009;12(2):270-7. DOI:10.1590/S1415790X2009000200016

22. Onis M de, Onyango AW, Borgui E, Siyam A, Nishida C, Siekmann J. Development of a WHO growth reference for school-aged children and adolescents. Bull World Health Organ. 2007;85(9):660-7.

23. Pinheiro ABV, Lacerda EMA, Benzecry EH, Gomes MCS, Costa VM. Tabela para avaliação de consumo alimentar em medidas caseiras. 4. ed. São Paulo: Atheneu; 2000.

24. Raper N, Perloff B, Ingwersen L, Steinfeldt L, Anand J. An overview of USDA's Dietary Intake Data System. J Food Compost Anal. 2004;17(3/4):545-55. DOI:10.1016/j.jfca.02.013

25. Santos JS, Costa MCO, Nascimento Sobrinho CL, Silva MCM, Souza KEP, Melo BO. Perfil antropométrico e consumo alimentar de adolescentes de Teixeira de Freitas - Bahia. Rev Nutr. 2005;18(5):623-32. DOI:10.1590/S1415-52732005000500005

26. Turrell G, Hewitt B, Patterson C, Oldenburg B. Measuring socio-economic position in dietary research: is choice of socio-economic indicator important? Public Health Nutr. 2003;6(2):191-200. DOI:10.1079/ PHN2002416

27. Variyam JN, Blaylock J, Smallwood D. Characterizing the distribution of macronutrient Intake among U.S. adults: a quantile regression approach. Am J Agric Econ. 2002;84(2):454-66.

28. World Cancer Research Fund; American Institute for Cancer Research. Food, nutrition, physical activity and the prevention of cancer: a global perspective. Washington, DC; 2007.

29. World Health Organization. Diet, nutrition and prevention of chronic diseases: report of a joint $\mathrm{WHO} /$ FAO expert consultation. Geneva; 2003. (WHO Technical Report Series, 916).

The research project was funded by the Conselho Nacional de Desenvolvimento Científico e Tecnológico (CNPq - National Process: 402111.05-2)

The authors declare no conflicts of interest. 